Supporting information for

Colloidal Synthesis of Lettuce-like Copper Sulfide for Light-Gating

Heterogeneous Nanochannels

Huan Wang, ${ }^{\dagger, \perp}$ Qian Liu, ${ }^{\dagger, \perp}$ Wenhua Li,${ }^{*}{ }^{, \dagger}$ Liping Wen, ${ }^{\dagger}$ Dong Zheng ${ }^{\S}$ Zhishan $\mathrm{Bo}^{*}, \dagger$ and Lei Jiang*

'Beijing Key Laboratory of Energy Conversion and Storage Materials, College of Chemistry, and ${ }^{\S}$ Analytical and Testing Center, Beijing Normal University, Beijing 100875, People's Republic of China

* Laboratory of Bioinspired Smart Interfacial Science, Technical Institute of Physics and Chemistry, Chinese Academy of Sciences, Beijing 100190, People's Republic of China

${ }^{\perp}$ H.W. and Q.L. contributed equally to the study.

*E-mail: 11112013119@bnu.edu.cn

*E-mail: zsbo@bnu.edu.cn

\title{
Content
}

1. Fabrication of Heterogeneous Nanochannels

2. Contact Angles Measurement

3. SEM Image of Product Obtained at Low Temperature

4. SEM Images of Products Fabricated in Different Reaction Time

5. The Absorption and Desorption of Mala from Lettuce-like $\mathrm{Cu}_{\mathrm{x}} \mathrm{S}$ Particles

6. Current-Voltage Characteristics of $\mathrm{AAO}-\mathrm{C} \mathrm{u}_{\mathrm{x}} \mathrm{S} / \mathrm{Mala}$ Heterogeneous Nanochannels

7. SEM Images of $\mathrm{AAO}-\mathrm{Cu}_{\mathrm{x}} \mathrm{S}$ Heterogeneous Nanochannels before and after Absorption with Mala

8. SEM Images of AAO-Cu $\mathrm{u}_{\mathrm{x}} \mathrm{S}$ Heterogeneous Nanochannels before and after Absorption with Spiro

9. Contact Angle Measurements of AAO-C $\mathrm{u}_{\mathrm{x}} \mathrm{S} / \mathrm{Spiro}$ Heterogeneous Nanochannels

10. Current Rectification Mechanism 


\section{Fabrication of Heterogeneous Nanochannels}

AAO- $\mathrm{Cu}_{\mathrm{x}} \mathrm{S}$ Heterogeneous Nanochannels: $53 \mathrm{mg}$ of as-synthesized $\mathrm{Cu}_{\mathrm{x}} \mathrm{S}$ (powder) with lettuce-like structure was dissolved in $6 \mathrm{~mL}$ chloroform. Uniform $\mathrm{Cu}_{\mathrm{x}} \mathrm{S}$ film was produced by spin-coating of the above solution on one side of anodic alumina (AAO, 20-30 nm) supporter at a spinning rate of $800 \mathrm{rpm}$ for $30 \mathrm{~s}$.

AAO- $\mathrm{Cu}_{\mathrm{x}} \mathrm{S} / \mathrm{Mala}$ Heterogeneous Nanochannels: $53 \mathrm{mg}$ lettuce-like $\mathrm{Cu}_{\mathrm{x}} \mathrm{S}$ (powder) and $34 \mathrm{mg}$ Malachite (Mala) was mixed in $6 \mathrm{~mL}$ chloroform to produce a $\mathrm{Cu}_{\mathrm{x}} \mathrm{S} / \mathrm{Mala}$ mixture solution. As-prepared solution was spin-coated on the AAO supporter (800 $\mathrm{rpm}, 30 \mathrm{~s}$ ) to form a uniform $\mathrm{AAO}-\mathrm{Cu}_{\mathrm{x}} \mathrm{S} / \mathrm{Mala}$ heterogeneous film.

AAO- $\mathrm{Cu}_{\mathrm{x}} \mathrm{S} /$ Spiro Heterogeneous Nanochannels: $53 \mathrm{mg}$ lettuce-like $\mathrm{Cu}_{\mathrm{x}} \mathrm{S}$ (powder) was dissolved in $6 \mathrm{~mL}$ chloroform. Then $32 \mathrm{mg}$ 1,3,3-Trimethylindolino-6'-nitrobenzopyrylospiran (Spiro) was added in the chloroform and a $\mathrm{Cu}_{\mathrm{x}} \mathrm{S}$ /Spiro mixture solution was produced. As-prepared solution was spin-coated on the AAO supporter $(800 \mathrm{rpm}, 30 \mathrm{~s})$ forming a uniform $\mathrm{AAO}-\mathrm{Cu}_{\mathrm{x}} \mathrm{S} /$ Spiro heterogeneous film.

\section{Contact Angles Measurement}

Contact angles were measured using an OCA20 instrument (DataPhysics, Germany). The system was maintained at ambient temperature and saturated humidity. In each measurement, a $2 \mu \mathrm{L}$ droplet of water was dispensed onto the surfaces under investigation. The average contact angel value was obtained from three different positions of the same sample.

\section{SEM Image of Product Obtained at Low Temperature}

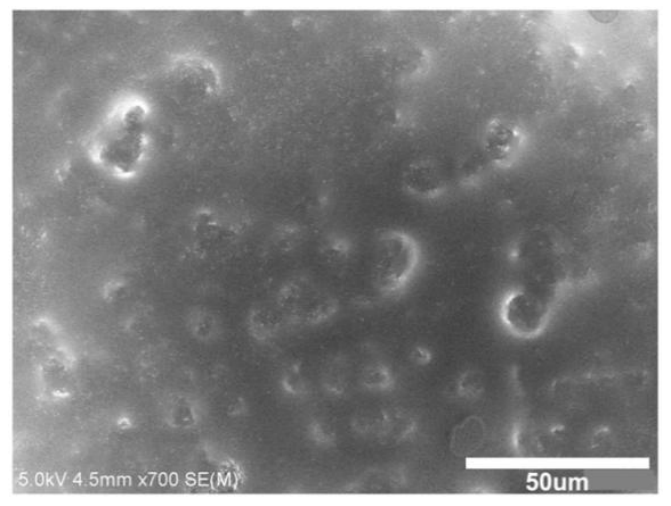

Figure S1. SEM image of product obtained at low temperature. 
SEM Images of Products Fabricated in Different Reaction Times

(a)

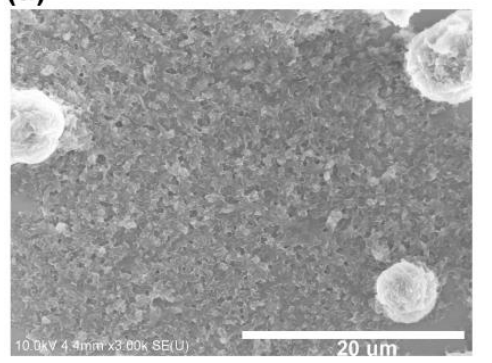

(d)

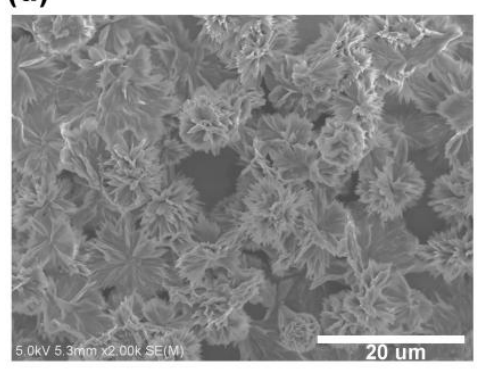

(b)

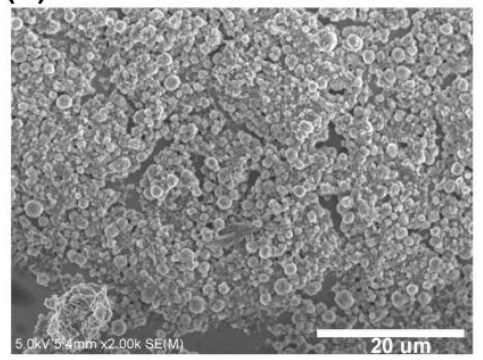

(e)

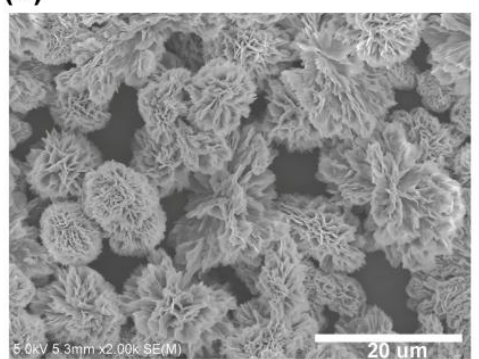

(c)

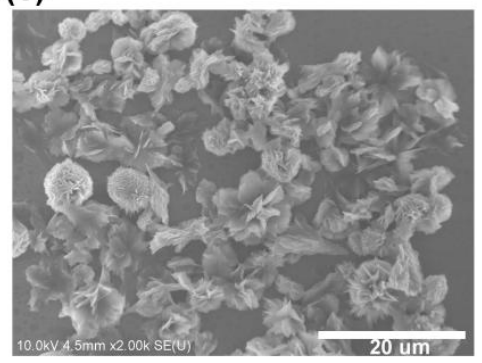

(f)

Figure S2. SEM Images of Products Fabricated in the Different Reaction Times of (a) 5, (b) 10, (c) 15, (d) 20, (e) 40, and (f) $100 \mathrm{~min}$

\section{The Absorption and Desorption of Mala from Lettuce-like $\mathrm{Cu}_{\mathrm{x}} \mathrm{S}$ Particles}

Mala is one kind of photoresponse molecule which will release hydroxide ions after irradiation with ultraviolet (UV) light. ${ }^{1}$ The transformation of Mala molecular structure before and after UV irradiation is shown in Figure S3a. Meanwhile, as shown in Figure S3b, Mala were added in different $\mathrm{pH}$ solutions $(>7$, about $7,<7$ ) before and after irradiation with UV light, respectively. It was observed that the Mala dissolved quickly in the solution at $\mathrm{pH}<7$ producing a dark blue solution and the solution under UV irradiation formed a light blue solution. Since Mala would also release hydroxide ions in an acid environment, it indicates that the positively charged Mala would easily dissolve in the solution. Based on this property, Mala was used in the $\mathrm{AAO}-\mathrm{Cu}_{\mathrm{x}} \mathrm{S} / \mathrm{Mala}$ heterogeneous nanochannels to regulate the ionic current through the nanochannels. Moreover, it demonstrated the process of absorption and desorption of Mala from the lettuce-like $\mathrm{Cu}_{\mathrm{x}} \mathrm{S}$ particles.

(a)

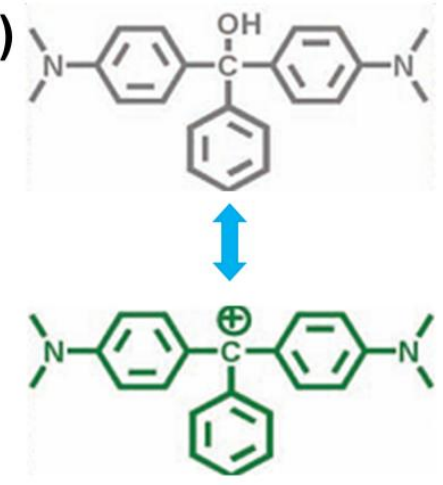

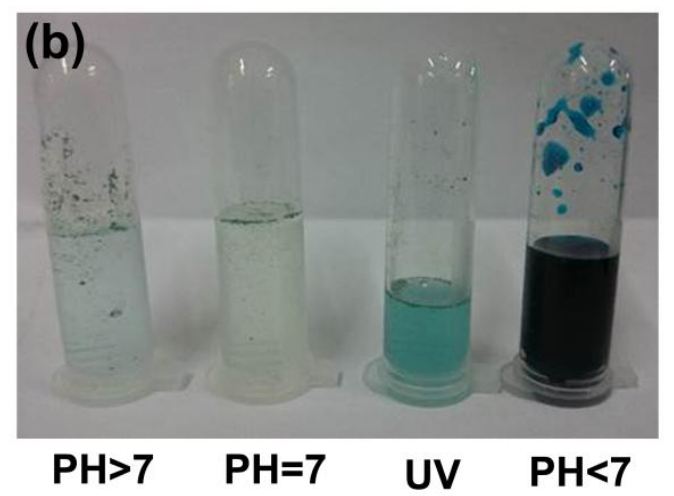

Figure S3. (a) Mala molecular structure before (top) and after (bottom) UV 
irradiation; (b) Solutions of Mala before $(\mathrm{pH}>7, \mathrm{pH} 7, \mathrm{pH}<7)$ and after UV irradiation ( $\mathrm{pH} 7)$.

\section{Current-Voltage Characteristics of AAO-C $\mathrm{Cu}_{\mathrm{x}} \mathrm{S} / \mathrm{Mala}$ Heterogeneous Nanochannels}

Current-voltage $(I-V)$ characteristics were made to evaluate the ionic transport properties of the heterogeneous nanochannels. As shown in Figure S4a, the AAO- $\mathrm{Cu}_{\mathrm{x}} \mathrm{S}$ heterogeneous nanochannels presented two similar $I-V$ curves in $0.01 \mathrm{M}$ $\mathrm{KCl}$ at $\mathrm{pH} 7$ before and after irradiation with UV light. The ionic current was about $-65 \mu \mathrm{A}$ at $-1.0 \mathrm{~V}$ and about $55 \mu \mathrm{A}$ at $+1.0 \mathrm{~V}$. Both the negative current and positive current were large showing no ionic rectification. However, for the AAO-Cu $\mathrm{S}$ /Mala heterogeneous nanochannel, obvious photoresponse property was observed. As shown in Figure S4b, after UV irradiation, the negative current was almost constant (about $-0.3 \mu \mathrm{A}$ at $-1.0 \mathrm{~V}$ ), whereas the positive current increased dramatically from about +0.1 to $+0.8 \mu \mathrm{A}$ at $+1.0 \mathrm{~V}$ indicating pronounced rectification behavior. The phenomenon fully demonstrated that the Mala was absorbed by the lettuce-like $\mathrm{Cu}_{\mathrm{x}} \mathrm{S}$ particles and became positively charged by releasing the hydroxide ions under UV light. However, with the test times increasing, the negative current and positive current simultaneously became larger and larger. When the AAO-Cu $\mathrm{S} / \mathrm{Mala}$ heterogeneous nanochannels (after irradiation with UV light) were tested for the fifth time, the rectification behavior totally disappeared (as shown in Figure S4c). This phenomenon can be explained by that the Mala was positively charged in a greater degree and gradually dissolved in $0.01 \mathrm{M} \mathrm{KCl}$ aqueous solution after irradiation with UV light (as we have discussed above), indicating the desorption process of Mala from $\mathrm{Cu}_{\mathrm{x}} \mathrm{S}$ particles. We also measured the ionic current of AAO-Cu $\mathrm{C}$ S/Mala heterogeneous nanochannels in $0.01 \mathrm{M} \mathrm{KCl}$ at different $\mathrm{pH}$ value. As shown in Figure S4d, in the solution of $\mathrm{pH} 2$, the ionic current of the AAO-Cu $\mathrm{C}$ S/Mala heterogeneous nanochannels was extremely large after $1 \mathrm{~min}$ (about $-65 \mu \mathrm{A}$ at $-1.0 \mathrm{~V}$ and about $+40 \mu \mathrm{A}$ at $+1.0 \mathrm{~V}$ ) which presented the thorough desorption process. Therefore, the lettuce-like $\mathrm{Cu}_{\mathrm{x}} \mathrm{S}$ particles can be used as an efficient carrier of functional organic molecule. 

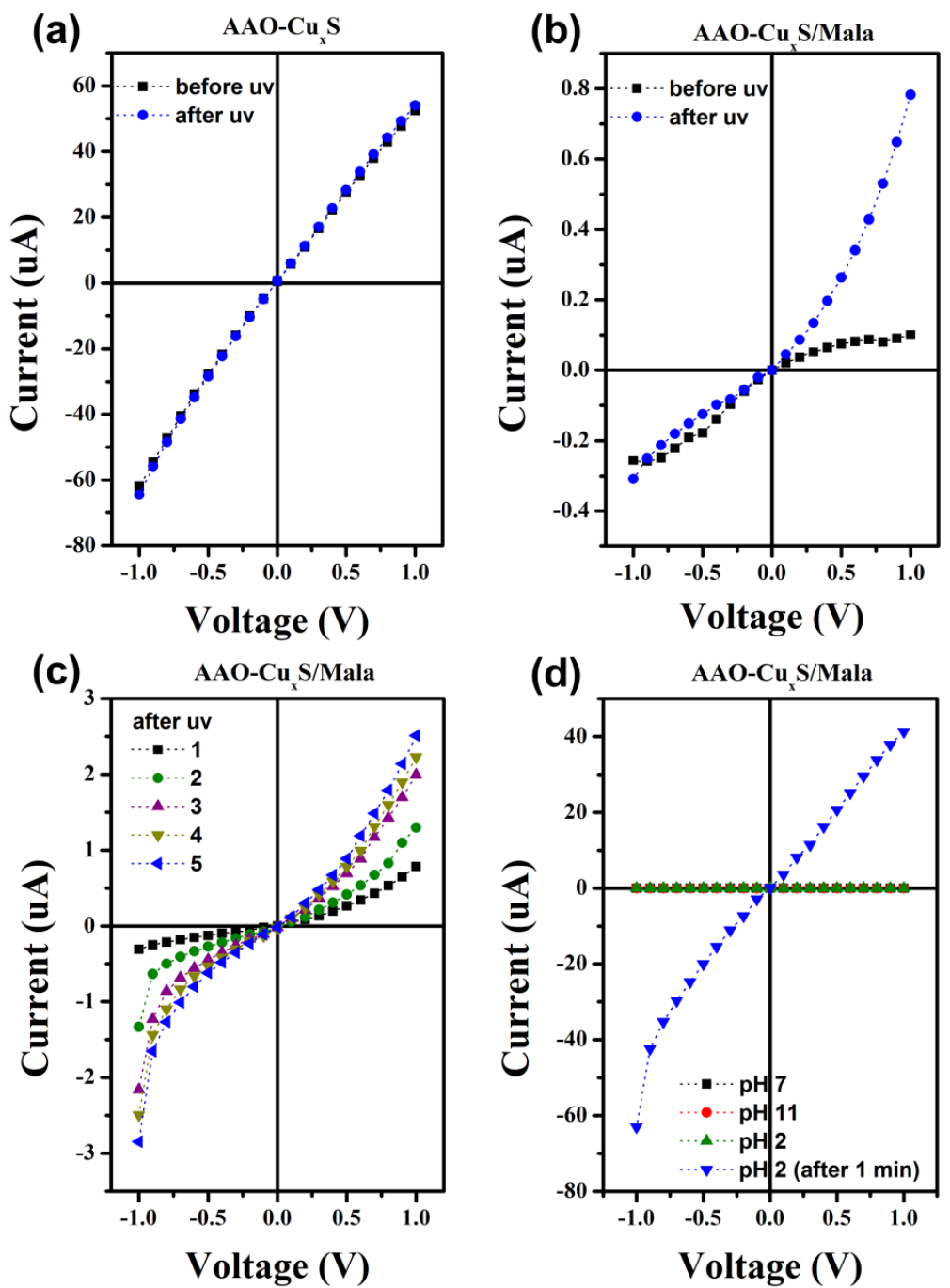

Figure S4. (a) Current-voltage curves of the AAO- $\mathrm{Cu}_{\mathrm{x}} \mathrm{S}$ heterogeneous nanochannels before (dark square) and after (blue circle) irradiation with UV light; (b) Current-voltage curves of the $\mathrm{AAO}-\mathrm{Cu}_{\mathrm{x}} \mathrm{S} / \mathrm{Mala}$ heterogeneous nanochannels before (dark square) and after (blue circle) irradiation with UV light tested for the first time; (c) Current-voltage curves of the $\mathrm{AAO}-\mathrm{Cu}_{\mathrm{x}} \mathrm{S} / \mathrm{Mala}$ heterogeneous nanochannels before (dark square) and after (blue circle) irradiation with UV light tested for the first (dark square), second (green circle), third (purple triangle), fourth (yellow triangle) and fifth (blue triangle) time; (d) Current-voltage curves of the AAO- $\mathrm{Cu}_{\mathrm{x}} \mathrm{S} / \mathrm{Mala}$ heterogeneous nanochannels in solutions at $\mathrm{pH} 7$ (dark square), $\mathrm{pH} 11$ (red circle), $\mathrm{pH}$ 2 (green triangle) and $\mathrm{pH} 2$ (blue triangle, tested after $1 \mathrm{~min}$ ), respectively.

SEM Images of AAO-Cu $\mathrm{S}$ Heterogeneous Nanochannels before and after Absorption with Mala

The SEM images of the nanochannels are shown in Figure S5. Before absorption of Mala, lettuce-like $\mathrm{Cu}_{\mathrm{x}} \mathrm{S}$ particles were with spokewise nanosheets. After absorption of Mala, the spokewise nanosheets were covered by Mala without destruction of the lettuce-like structure. However, after desorption of Mala, the spokewise nanosheets 
were recovered.

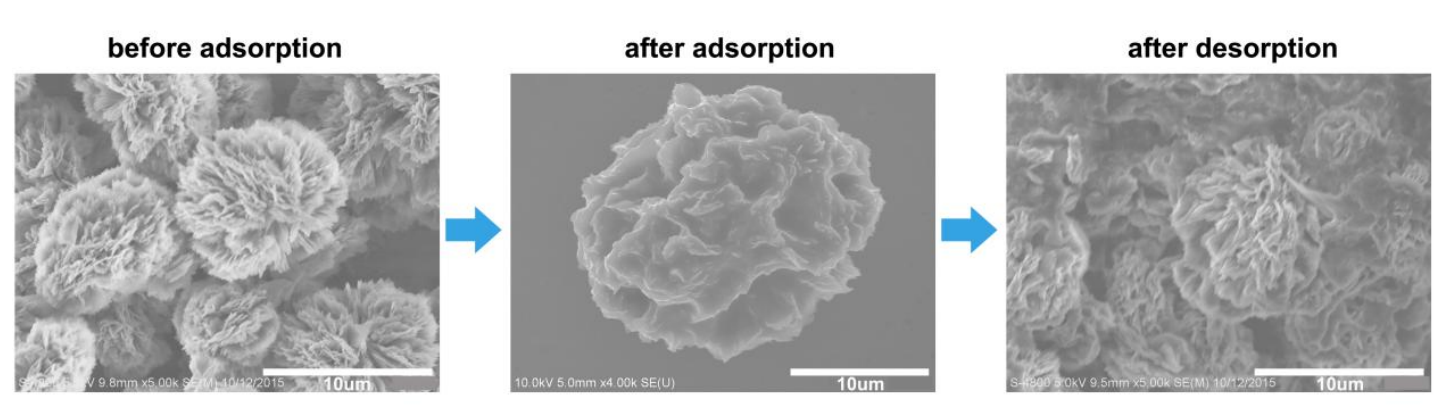

Figure S5. SEM images of the AAO-Cu $u_{x} S$ heterogeneous nanochannels before adsorption of Mala (before adsorption), AAO-Cu $\mathrm{Cu}_{\mathrm{x}} \mathrm{S} / \mathrm{Mala}$ heterogeneous nanochannels after adsorption of Mala (after adsorption), AAO- $\mathrm{Cu}_{\mathrm{x}} \mathrm{S}$ heterogeneous nanochannels after desorption of Mala (after desorption).

\section{SEM Images of AAO-Cu $\mathrm{Cu}_{\mathrm{x}} \mathrm{S}$ Heterogeneous Nanochannels before and after Absorption with Spiro}

The SEM images of AAO- $\mathrm{Cu}_{\mathrm{x}} \mathrm{S}$ and $\mathrm{AAO}-\mathrm{Cu}_{\mathrm{x}} \mathrm{S} / \mathrm{Sp}$ iro heterogeneous nanochannel are shown in Figure S6 and Figure S7. It was obvious that after absorption of Spiro, the lettuce-like structure of $\mathrm{Cu}_{\mathrm{x}} \mathrm{S}$ particles was remained. The contact angle measurements in Figure S8 showed that contact angles of the AAO-Cu $\mathrm{S}$ heterogeneous nanochannels, $\mathrm{AAO}-\mathrm{Cu}_{\mathrm{x}} \mathrm{S} / \mathrm{Sp}$ iro heterogeneous nanochannels before and after irradiation with UV light are almost the same. It indicates that the absorption of Spiro and UV irradiation have no obvious influence on the wettability of the nanochannels.
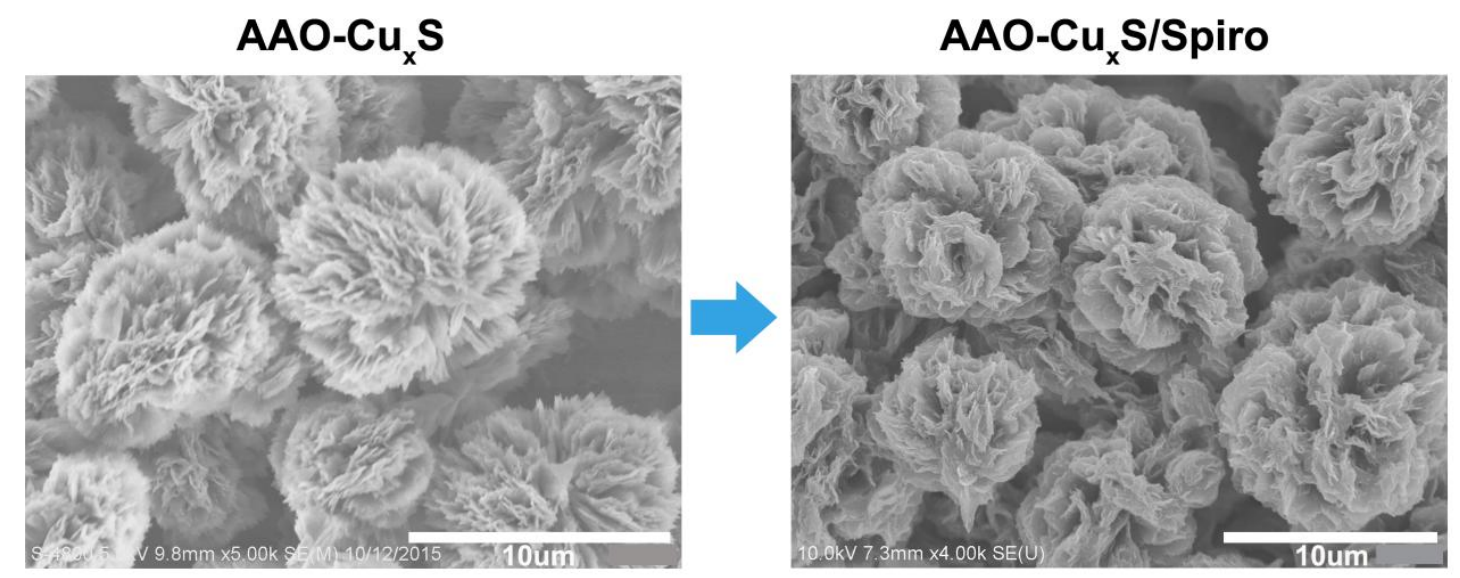

Figure S6. SEM images of the AAO- $\mathrm{Cu}_{\mathrm{x}} \mathrm{S}$ heterogeneous nanochannels and $\mathrm{AAO}-\mathrm{Cu}_{\mathrm{x}} \mathrm{S} /$ Spiro heterogeneous nanochannels. 

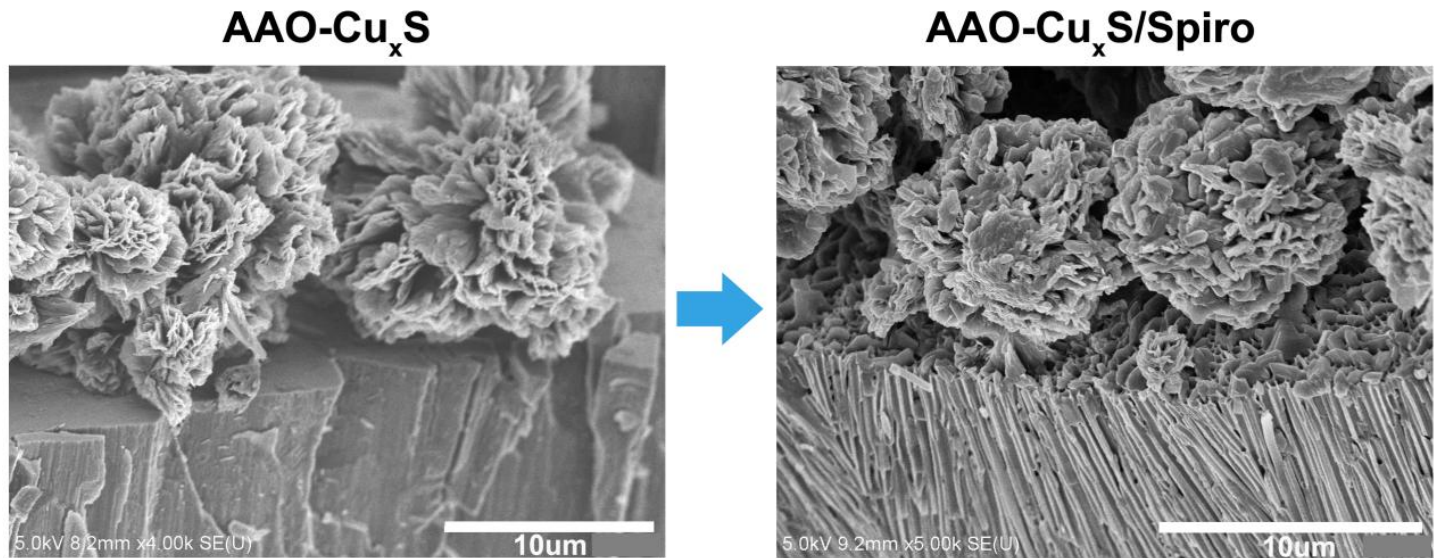

Figure S7. SEM cross section of the AAO- $\mathrm{Cu}_{\mathrm{x}} \mathrm{S}$ heterogeneous nanochannels and $\mathrm{AAO}-\mathrm{Cu}_{\mathrm{x}} \mathrm{S} /$ Spiro heterogeneous nanochannels.

\section{Contact Angle Measurements of AAO-Cu $\mathrm{Cu}$ S/Spiro Heterogeneous Nanochannels}

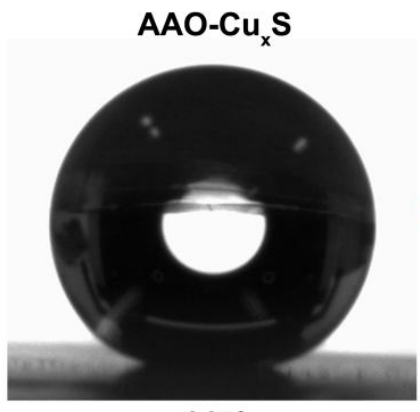

$147^{\circ}$

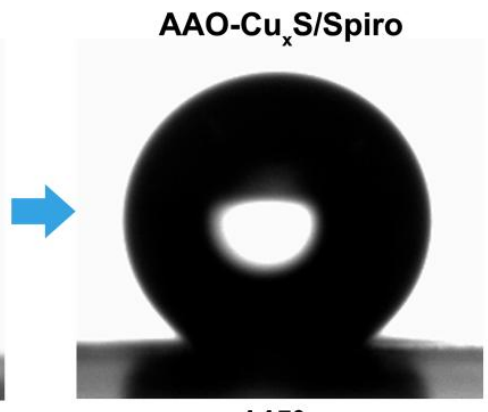

$145^{\circ}$

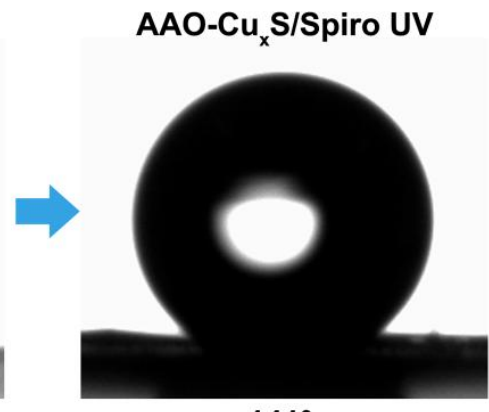

$141^{\circ}$

Figure S8. Contact angle measurements of $\mathrm{AAO}-\mathrm{Cu}_{\mathrm{x}} \mathrm{S}$ heterogeneous nanochannels, AAO- $\mathrm{Cu}_{\mathrm{x}} \mathrm{S} / \mathrm{Spiro}$ heterogeneous nanochannels and $\mathrm{AAO}-\mathrm{Cu}_{\mathrm{x}} \mathrm{S} /$ Spiro heterogeneous nanochannels after irradiation of UV light.

\section{Current Rectification Mechanism}

For the AAO nanochannels, no obvious current rectification phenomenon is obtained. However, after coating with $\mathrm{Cu}_{\mathrm{x}} \mathrm{S}$ or $\mathrm{Cu}_{\mathrm{x}} \mathrm{S} / \mathrm{Spiro}$, the current rectification phenomenon is observed. This current rectification is caused by asymmetric ion transport through nanochannels. The asymmetric ion transport properties can be result from nanopore geometry, surface charge distribution, different chemical composition, and traverse wettability differences. ${ }^{2}$ Under neutral solution condition, the inner surface of AAO nanochannels has some positive charge, so the migration of anions through the nanochannels predominates. ${ }^{3}$ For the AAO nanochannels, no obvious current rectification phenomenon is obtained because of symmetrical potential distribution and cylindrical structure. After coating with $\mathrm{Cu}_{\mathrm{x}} \mathrm{S}$ or $\mathrm{Cu}_{\mathrm{x}} \mathrm{S} / \mathrm{Spiro}$, asymmetric nanochannel structure and wettability form, leading to the asymmetric anions transport through the heterogeneous nanochannels. As shown in Figure S9, the anode faces the AAO nanochannels, and the cathode faces the $\mathrm{Cu}_{\mathrm{x}} \mathrm{S}$ or $\mathrm{Cu}_{\mathrm{x}} \mathrm{S} / \mathrm{Sp}$ iro 
nanoparticles. At negative scan voltage, the anions migrate from $\mathrm{AAO}$ to $\mathrm{Cu}_{\mathrm{x}} \mathrm{S}$; at positive scan voltage, the anions migrate from $\mathrm{Cu}_{\mathrm{x}} \mathrm{S}$ to $\mathrm{AAO}$. Due to the $\mathrm{Cu}_{\mathrm{x}} \mathrm{S}$ nanoparticles are much more hydrophobic than AAO nanochannels, so the migration of anions from $\mathrm{AAO}$ to $\mathrm{Cu}_{\mathrm{x}} \mathrm{S}$ is easier than it from $\mathrm{Cu}_{\mathrm{x}} \mathrm{S}$ to $\mathrm{AAO}$, which causes the current value at negative scan voltage is large than it at positive scan voltage and current rectification phenomenon.

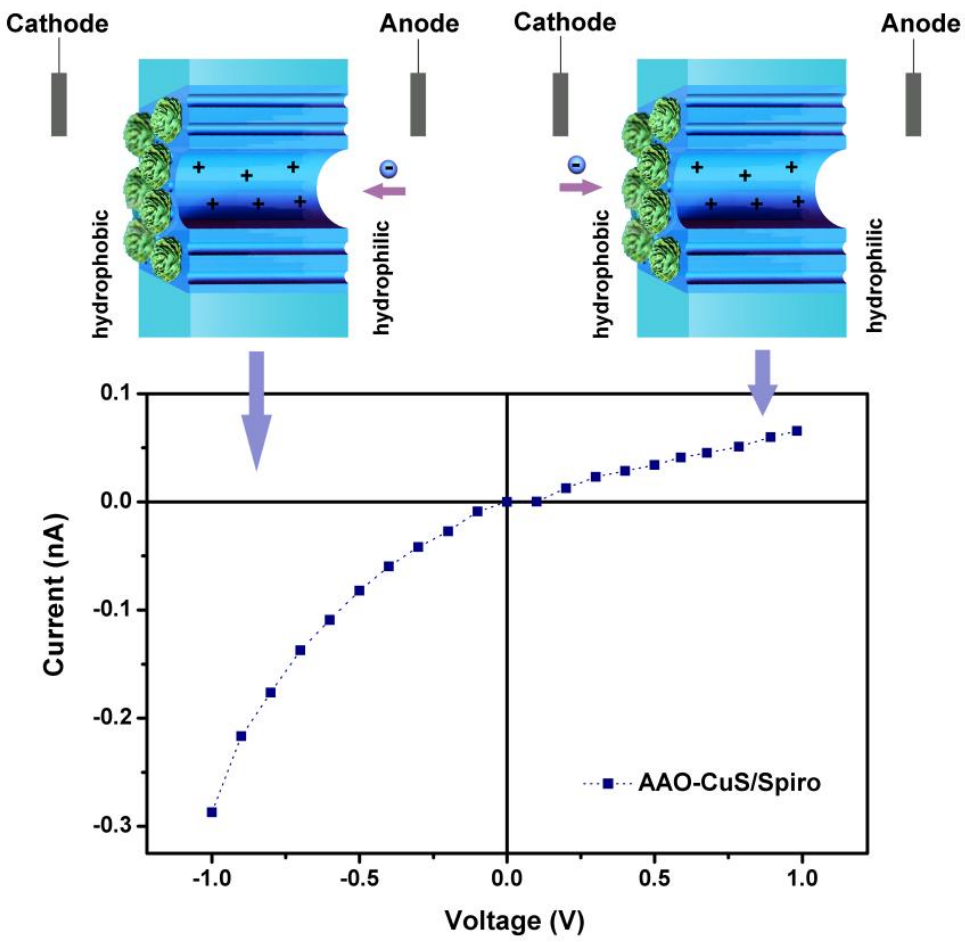

Figure S9. Schematic of current rectification mechanism.

\section{References}

1. Wen, L.; Liu, Q.; Ma, J.; Tian, Y.; Li, C.; Bo, Z.; Jiang, L. Malachite Green Derivative-Functionalized Single Nanochannel: Light-and-pH Dual-Driven Ionic Gating. Adv. Mater. 2012, 24, 6193-6198.

2. Guo, W.; Tian, Y.; Jiang, L., Asymmetric Ion Transport through Ion-Channel-Mimetic Solid-State Nanopores. Acc. Chem. Res. 2013, 46, 2834-2846.

3. Zhang, Z.; Kong, X.-Y.; Xiao, K.; Xie, G.; Liu, Q.; Tian, Y.; Zhang, H.; Ma, J.; Wen, L.; Jiang, L. A Bioinspired Multifunctional Heterogeneous Membrane with Ultrahigh Ionic Rectification and Highly Efficient Selective Ionic Gating. Adv. Mater. 2016, 28, 144-150. 